\title{
Effects of Intercropping with Hyperaccumulator plants on Nutrient Uptake of Grape Seedlings under Cadmium Stress
}

\author{
Kewen Huang ${ }^{1, a}$, Jianhua Li ${ }^{2, b}$, Lijin Lin ${ }^{3, c}$, Wei Jiang ${ }^{4, d}$ and Ming'an Liao ${ }^{1, e^{*}}$ \\ ${ }^{1}$ College of Horticulture, Sichuan Agricultural University, Chengdu, Sichuan, China \\ ${ }^{2}$ Sichuan Ya'an Municipal Product Quality Supervision \& Inspection Institute, Ya'an, Sichuan, China \\ ${ }^{3}$ Institute of Pomology and Olericulture, Sichuan Agricultural University, Chengdu, Sichuan, China \\ ${ }^{4}$ College of Chemistry and Life Science, Chengdu Normal University, Chengdu, Sichuan, China \\ a263733029@qq.com, b710753781@qq.com, Nlj800924@163.com, d1399945180@qq.com, \\ eIman@sicau.edu.cn
}

${ }^{*}$ Corresponding author. Kewen Huang, Jianhua Li and Lijin Lin contributed equally to this work.

Keywords: Grape; Intercropping; Nutrient uptake; Hyperaccumulator plants; Cadmium stress Abstract: A pot experiment was carried out to study the effects of intercropping with four cadmium (Cd) hyperaccumulator plants (Galinsoga parviflora, Sigesbeckia orientalis, Solanum nigrum, Crassocephalum crepidioides) on nutrient uptake of grape seedlings under Cd stress. When grape seedlings intercropped with G. parviflora, S. orientalis, S. nigrum and C. crepidioides, the total nitrogen $(\mathrm{N})$, total phosphorus $(\mathrm{P})$ and total potassium $(\mathrm{K})$ contents in grape seedlings decreased compared with the monoculture under $\mathrm{Cd}$ stress. Grape intercropped hyperaccumulator plants had no significant effects or reduced the soil alkali soluble $\mathrm{N}$, soil available $\mathrm{P}$ and soil available $\mathrm{K}$ concentrations. Therefore, intercropping with hyperaccumulator plants decreased the nutrient absorption of grape seedlings under Cd stress.

\section{Introduction}

With increasing industrialization and disturbance of natural biogeochemical cycles, the problem of heavy metals' pollution is becoming more and more serious [1]. Cadmium $(\mathrm{Cd})$ is one of the most problematic non-essential heavy metals, which is not conducive to plant growth [2]. Grape is widely cultivated around the word and global grape orchards have increased rapidly in recent years [3]. However, the current individual grape orchards have been subject to heavy metal pollution, which to some extent inhibited the growth of grapes [4].

Intercropping could make full use of light, heat, water, soil and other resources [5]. The study found that intercropping grass in the orchard line could prevent water loss, fertilize the soil and promote fruit tree growth [6-7]. In addition, intercropping with Cd-hyperaccumulator plants is confirmed to be beneficial to plant uptake of nutrients in Cd-contaminated soil [8]. Galinsoga parviflora [9], Sigesbeckia orientalis [10], Solanum nigrum [11] and Crassocephalum crepidioides [12] are Cd-hyperaccumulator plants. In this study, G. parviflora, S. orientalis, S. nigrum and C. crepidioides were used to intercropped with grape seedlings in Cd-contaminated soil, and the effects of intercropping with hyperaccumulator plants on nutrient uptake of grape seedlings were studied. The aim of this study was to screen out the best hyperaccumulator plant which could promote the nutrient absorption of grape.

\section{Materials and Methods}

Materials. In April, 2016, the seeds of hyperaccumulator plants (G. parviflora, S. orientalis, $S$. nigrum and $C$. crepidioides) were collected from the farmland of Chengdu Campus of Sichuan Agricultural University. Then, the seeds were put in the climate chamber to germinate and further cultivation and transplanting. The cultivar of grape is Kyoho with cutting seedlings. The fluvo-aquic 
soil samples were collected from the farmland at Chengdu Campus of Sichuan Agricultural University in April, 2016.

Experimental Design. The experiment was conducted in Chengdu Campus of Sichuan Agricultural University from April to July 2016. In April 2016, the soil was air-dried and passed through a 6.72-mm sieve. $3 \mathrm{~kg}$ air-dried soil was weighed into each plastic pot $(21 \mathrm{~cm}$ high, $20 \mathrm{~cm}$ in diameter), soaking uniformly by $5 \mathrm{mg} / \mathrm{kg} \mathrm{Cd}$ (in the form of $\mathrm{CdCl}_{2} \cdot 2.5 \mathrm{H}_{2} \mathrm{O}$ ) solution for 4 weeks. All pots were watered each day to keep the soil moisture about $80 \%$, and dug aperiodically to make soil mixed fully. In May 2016, three uniform-sized cutting seedlings (the shoots were about $15 \mathrm{~cm}$ ) of Kyoho grape were transplanted into each pot for monoculture and two of them for intercropping, respectively. One uniform-sized seedling (two pairs leaves expanded) of each huperaccumulator plant were transplanted into each pot for intercropping. The five treatments in experiment were monoculture of grape, grape intercropped with $G$. parviflora, grape intercropped with $S$. orientalis, grape intercropped with $S$. nigrum and grape intercropped with $C$. crepidioides. For each treatment with three replicates and the pots placed completely random. The distance between pots was $15 \mathrm{~cm}$, and the pot position exchanged aperiodically to weaken the impact of the marginal effects. The soil moisture content was maintained at $80 \%$ of field capacity until the plants were harvested.

After 60 days, the grape seedlings were dug up and divided into three parts of root, stem, leaf, then washed with tap water firstly, followed by deionized water. After that, the organs of all plants were dried at $80{ }^{\circ} \mathrm{C}$ until constant weight, weighed, ground to $<0.149 \mathrm{~mm}$, and sealed into plastic bags for the determination of total nitrogen $(\mathrm{N})$, total phosphorus $(\mathrm{P})$ and total potassium $(\mathrm{K})$ contents [13]. The soil sample was collected, air-dried and ground to $<1.0 \mathrm{~mm}$ for analysis of alkali soluble $\mathrm{N}$, available $\mathrm{P}$ and available $\mathrm{K}$ concentrations [13].

Statistical Analyses. Statistical analyses were conducted using statistical software of SPSS 17.0. Data were analyzed by one-way ANOVA with least significant difference at $5 \%$ confidence level.

\section{Results and Discussion}

Total N Contents in Grape Seedlings. Intercropping significantly decreased the N content in stems of grape seedlings compared with the monoculture (Table 1). The $\mathrm{N}$ content in leaves of grape seedlings was ranked as: monoculture > intercropping with $G$. parviflora > intercropping with $S$. orientalis > intercropping with $S$. nigrum > intercropping with $C$. crepidioides. Compared with the monoculture, intercropping with $C$. crepidioides had little effect on the $\mathrm{N}$ content in roots of grape seedlings, and the other treatments significantly decreased the $\mathrm{N}$ contents in their roots $(P<0.05)$. Intercropping with $G$. parviflora, $S$. orientalis, $S$. nigrum and $C$. crepidioides significantly decreased the $\mathrm{N}$ contents in shoots of grape seedlings, which decreased by $6.68 \%(P<0.05), 16.18 \%(P<0.05), 21.28 \%(P<0.05)$, and $21.20 \%(P<0.05)$, respectively, compared with the monoculture.

Table 1 Total $\mathrm{N}$ contents in grape seedlings under Cd stress

\begin{tabular}{|l|c|c|c|c|}
\hline \multicolumn{1}{|c|}{ Treatments } & $\begin{array}{c}\text { Roots } \\
(\mathrm{mg} / \mathrm{g})\end{array}$ & $\begin{array}{c}\text { Stems } \\
(\mathrm{mg} / \mathrm{g})\end{array}$ & $\begin{array}{c}\text { Leaves } \\
(\mathrm{mg} / \mathrm{g})\end{array}$ & $\begin{array}{c}\text { Shoots } \\
(\mathrm{mg} / \mathrm{g})\end{array}$ \\
\hline Monoculture & $10.61 \pm 0.21 \mathrm{a}$ & $4.67 \pm 0.32 \mathrm{a}$ & $14.67 \pm 0.93 \mathrm{a}$ & $11.37 \pm 0.72 \mathrm{a}$ \\
\hline Intercropping with G. parviflora & $6.80 \pm 0.56 \mathrm{~d}$ & $2.97 \pm 0.17 \mathrm{c}$ & $14.06 \pm 1.07 \mathrm{~b}$ & $10.61 \pm 0.79 \mathrm{~b}$ \\
\hline Intercropping with $S$. orientalis & $8.66 \pm 0.77 \mathrm{c}$ & $4.26 \pm 0.15 \mathrm{~b}$ & $11.75 \pm 0.75 \mathrm{c}$ & $9.53 \pm 0.69 \mathrm{c}$ \\
\hline Intercropping with $S$. nigrum & $9.98 \pm 0.53 \mathrm{~b}$ & $3.12 \pm 0.23 \mathrm{c}$ & $11.69 \pm 0.88 \mathrm{c}$ & $8.95 \pm 0.74 \mathrm{~d}$ \\
\hline Intercropping with C. crepidioides & $10.58 \pm 0.68 \mathrm{a}$ & $3.04 \pm 0.26 \mathrm{c}$ & $11.58 \pm 1.31 \mathrm{c}$ & $8.96 \pm 0.73 \mathrm{~d}$ \\
\hline
\end{tabular}

Values are means \pm standard errors. Means with the same letter within each column are not significantly different at $p<0.05$.

Total P Contents in Grape Seedlings. Intercropping significantly decreased P content in leaves of grape seedlings compared with the monoculture (Table 2). The $\mathrm{P}$ content in stems of grape seedlings was ranked as: monoculture > intercropping with $S$. nigrum > intercropping with G. parviflora > intercropping with $S$. orientalis > intercropping with $C$. crepidioides. Compared with the monoculture, 
intercropping with $C$. crepidioides had little effect on the $\mathrm{P}$ content in roots of grape seedlings, and the other treatments significantly decreased the $\mathrm{P}$ content of its roots $(P<0.05)$. Intercropping with $G$. parviflora, $S$. orientalis, $S$. nigrum and $C$. crepidioides significantly decreased the $\mathrm{P}$ content in shoots of grape seedlings, which decreased by $23.19 \%(P<0.05), 21.93 \%(P<0.05), 18.60 \%(P<0.05)$, and $26.41 \%(P<0.05)$, respectively compared with the monoculture.

Table 2 Total $\mathrm{P}$ contents in grape seedlings under Cd stress

\begin{tabular}{|l|c|c|c|c|}
\hline \multicolumn{1}{|c|}{ Treatments } & $\begin{array}{c}\text { Roots } \\
(\mathrm{mg} / \mathrm{g})\end{array}$ & $\begin{array}{c}\text { Stems } \\
(\mathrm{mg} / \mathrm{g})\end{array}$ & $\begin{array}{c}\text { Leaves } \\
(\mathrm{mg} / \mathrm{g})\end{array}$ & \multicolumn{1}{c|}{$\begin{array}{c}\text { Shoots } \\
(\mathrm{mg} / \mathrm{g})\end{array}$} \\
\hline Monoculture & $1.394 \pm 0.07 \mathrm{a}$ & $0.623 \pm 0.08 \mathrm{a}$ & $0.988 \pm 0.07 \mathrm{a}$ & $0.871 \pm 0.32 \mathrm{a}$ \\
\hline Intercropping with G. parviflora & $1.348 \pm 0.08 \mathrm{~b}$ & $0.575 \pm 0.01 \mathrm{~b}$ & $0.709 \pm 0.03 \mathrm{~cd}$ & $0.669 \pm 0.29 \mathrm{bc}$ \\
\hline Intercropping with $S$. orientalis & $1.294 \pm 0.07 \mathrm{c}$ & $0.568 \pm 0.05 \mathrm{~b}$ & $0.731 \pm 0.01 \mathrm{bc}$ & $0.680 \pm 0.19 \mathrm{bc}$ \\
\hline Intercropping with S. nigrum & $1.293 \pm 0.06 \mathrm{c}$ & $0.616 \pm 0.02 \mathrm{a}$ & $0.749 \pm 0.08 \mathrm{~b}$ & $0.709 \pm 0.24 \mathrm{~b}$ \\
\hline Intercropping with C.crepidioides & $1.395 \pm 0.13 \mathrm{a}$ & $0.540 \pm 0.06 \mathrm{c}$ & $0.688 \pm 0.07 \mathrm{~d}$ & $0.641 \pm 0.18 \mathrm{c}$ \\
\hline
\end{tabular}

Values are means \pm standard errors. Means with the same letter within each column are not significantly different at $p<0.05$.

Total K Contents in Grape Seedlings. Intercropping significantly decreased the K content in leaves of grape seedlings compared with the monoculture (Table 3). The K content in stems of grape seedlings was ranked as: monoculture > intercropping with $S$. orientalis > intercropping with $S$. nigrum > intercropping with G. parviflora > intercropping with $C$. crepidioides. Compared with the monoculture, intercropping with $C$. crepidioides had little effect on the $\mathrm{K}$ content in roots of grape seedlings, and the other treatments significantly decreased the $\mathrm{K}$ contents in their roots $(P<0.05)$. Intercropping with $G$. parviflora, S. orientalis, $S$. nigrum and $C$. crepidioides significantly decreased the $\mathrm{K}$ contents in shoots of grape seedlings, which decreased by $33.13 \%(P<0.05), 12.96 \%(P<0.05)$, $20.00 \%(P<0.05)$, and $30.35 \%(P<0.05)$, respectively, compared with the monoculture.

Table 3 Total $\mathrm{K}$ contents in grape seedlings under Cd stress

\begin{tabular}{|l|c|c|c|c|}
\hline \multicolumn{1}{|c|}{ Treatments } & $\begin{array}{c}\text { Roots } \\
(\mathrm{mg} / \mathrm{g})\end{array}$ & $\begin{array}{c}\text { Stems } \\
(\mathrm{mg} / \mathrm{g})\end{array}$ & $\begin{array}{c}\text { Leaves } \\
(\mathrm{mg} / \mathrm{g})\end{array}$ & $\begin{array}{c}\text { Shoots } \\
(\mathrm{mg} / \mathrm{g})\end{array}$ \\
\hline Monoculture & $17.63 \pm 0.62 \mathrm{a}$ & $9.28 \pm 0.58 \mathrm{a}$ & $12.54 \pm 0.53 \mathrm{a}$ & $11.50 \pm 0.62 \mathrm{a}$ \\
\hline Intercropping with G. parviflora & $16.09 \pm 0.71 \mathrm{~b}$ & $6.02 \pm 0.51 \mathrm{~b}$ & $8.43 \pm 0.47 \mathrm{~d}$ & $7.69 \pm 0.79 \mathrm{~d}$ \\
\hline Intercropping with $S$. orientalis & $12.70 \pm 0.64 \mathrm{c}$ & $8.76 \pm 0.75 \mathrm{a}$ & $10.59 \pm 0.57 \mathrm{~b}$ & $10.01 \pm 0.82 \mathrm{~b}$ \\
\hline Intercropping with . nigrum & $12.65 \pm 0.58 \mathrm{c}$ & $6.25 \pm 0.62 \mathrm{~b}$ & $10.58 \pm 0.68 \mathrm{~b}$ & $9.20 \pm 0.44 \mathrm{c}$ \\
\hline Intercropping with C.crepidioides & $18.04 \pm 0.86 \mathrm{a}$ & $4.99 \pm 0.56 \mathrm{c}$ & $9.39 \pm \pm 0.61 \mathrm{c}$ & $8.01 \pm 0.68 \mathrm{~d}$ \\
\hline
\end{tabular}

Values are means \pm standard errors. Means with the same letter within each column are not significantly different at $p<0.05$.

Soil Alkali Soluble N, Available P and Available K Concentrations. Compared with the monoculture, intercropping had little effect on alkali soluble $\mathrm{N}$ concentration of soil (Table 4). When the grap seedlings intercropped with G. parviflora, S. orientalis, S. nigrum and C. Crepidioides, the available $\mathrm{P}$ concentrations of soil significantly reduced, which reduced by $18.03 \%(P<0.05), 27.06 \%$ $(P<0.05), 17.63 \%(P<0.05)$, and $16.98 \%(P<0.05)$, respectively, compared with the monoculture. The available K concentration of soil was ranked as grape intercropped with $C$. crepidioides $>$ grape monoculture > grape intercropped with $S$. nigrum $>$ grape intercropped with $S$. orientalis $>$ grape intercropped with G. parviflora.

\section{Conclusions}

When grape seedlings intercropped with G. parviflora, S. orientalis, S. nigrum and C. crepidioides, the total $\mathrm{N}$, total $\mathrm{P}$ and total $\mathrm{K}$ contents in grape seedlings decreased compared with the monoculture under Cd stress. Grape intercropped hyperaccumulator plants had no significant effects or reduced the 
soil alkali soluble $\mathrm{N}$, soil available $\mathrm{P}$ and soil available $\mathrm{K}$ concentrations. These results indicate that intercropping with hyperaccumulator plants decreased the nutrient absorption of grape seedlings under Cd stress.

Table 4 Soil alkali soluble N, available $\mathrm{P}$ and available K concentrations

\begin{tabular}{|c|c|c|c|}
\hline Treatments & $\begin{array}{c}\text { Alkali soluble N } \\
(\mathrm{mg} / \mathrm{kg})\end{array}$ & $\begin{array}{c}\text { Available P } \\
(\mathrm{mg} / \mathrm{kg})\end{array}$ & $\begin{array}{c}\text { Available K } \\
(\mathrm{mg} / \mathrm{kg})\end{array}$ \\
\hline Grape monoculture & $115.82 \pm 2.51 \mathrm{a}$ & $32.22 \pm 1.07 \mathrm{a}$ & $117.50 \pm 3.52 \mathrm{a}$ \\
\hline Grape intercropped with G. parviflora & $114.51 \pm 3.77 \mathrm{a}$ & $26.41 \pm 0.98 \mathrm{~b}$ & $77.45 \pm 2.24 \mathrm{c}$ \\
\hline Grape intercropped with S. orientalis & $122.83 \pm 1.46 \mathrm{a}$ & $23.50 \pm 1.32 \mathrm{c}$ & $92.47 \pm 3.21 \mathrm{~b}$ \\
\hline Grape intercropped with S. nigrum & $116.61 \pm 3.87 \mathrm{a}$ & $26.54 \pm 2.41 \mathrm{~b}$ & $114.98 \pm 4.68 \mathrm{a}$ \\
\hline Grape intercropped with C.crepidioides & $116.20 \pm 3.79 \mathrm{a}$ & $26.75 \pm 1.33 \mathrm{~b}$ & $119.95 \pm 3.79 \mathrm{a}$ \\
\hline
\end{tabular}

Values are means \pm standard errors. Means with the same letter within each column are not significantly different at $p<0.05$.

\section{Acknowledgements}

This work was financially supported by the Application Infrastructure Project of Science and Technology Department of Sichuan Province (2016JY0258).

\section{References}

[1] H. Ali, E. Khan and M.A. Sajad: Chemosphere Vol. 91 (2013), p. 869.

[2] K.J. Peng, C.L. Luo, Y.H. Chen, G.P. Wang and Z.G. Shen: Bulletin of Environmental Contamination and Toxicology Vol. 83 (2009), p. 260.

[3] J.F. Meng, T.C. Shi, S. Song, Z.W. Zhang and Y.L. Fang: Food Chemistry Vol. 231 (2017), p. 185.

[4] X.J. Shao, H.Q. Yang, H.T. Qiao, L. Zhang and S.Z. You: Chinese Journal of Applied Ecology Vol. 20 (2009), p. 1390.

[5] L. Li, X.L. Li, F.S. Zhang, J.H. Sun, S.C. Yang and M.J. Lu: Plant Nutrition and Fertilizer Science Vol. 6 (2000), p. 140.

[6] Q.X. Chen, J.S. Liao, G.H. Zheng and S. Liu: Journal of Fujian Agricultural University Vol. 25 (1996), p. 429.

[7] H. Li, Z.M. Hui, Z.W. Zhang, Y.M. Huang and E.H. Li: Transactions of the CSAE Vol. 20 (2004), p. 116.

[8] J. Shi, T.Y. Huang, X.D. Chu, L.J. Lin and M.A. Liao: Acta Agriculturae Universitatis Jiangxiensis Vol. 37 (2015), p. 231.

[9] L. Lin, Q. Jin, Y. Liu, B. Ning, M.A. Liao and L. Luo: Environmental Toxicology and Chemistry Vol. 33 (2014), p. 2422.

[10]S. Zhang, H. Lin, L. Deng, G.S. Gong, Y.X. Jia, X.X. Xu, T. Li, Y. Li and H. Chen: Ecological Engineering Vol. 51 (2013), p. 133.

[11]S.H. Wei, Q.X. Zhuo, X. Wang, K.S. Zhang, G.L. Guo and L.Q.Y. Ma: Chinese Science Bulletin Vol. 50 (2005), p. 33.

[12]Y. Masahide, Y. Satoshi and I. Koji: Soil Science and Plant Nutrition Vol. 54 (2008), p. 738.

[13]S.D. Bao: Agrochemical Soil Analysis (3rd edition, China Agriculture Press, Beijing, China 2000). 